\title{
Hepatocyte-specific, PPAR $\gamma$-regulated mechanisms to promote steatosis in adult mice
}

\author{
Abigail Wolf Greenstein 1,2,3,*, Neena Majumdar,,2,*, Peng Yang1,2, \\ Papasani V Subbaiah 1,2, Rhonda D Kineman ${ }^{1,2}$ and Jose Cordoba-Chacon 1,2 \\ ${ }^{1}$ Research and Development Division, Jesse Brown Veterans Affairs Medical Center, Chicago, Illinois, USA \\ 2Section of Endocrinology, Diabetes, and Metabolism, Department of Medicine, University of Illinois at Chicago, \\ Chicago, Illinois, USA \\ ${ }^{3}$ Biologic Resources Laboratory, University of Illinois at Chicago, Chicago, Illinois, USA \\ *(A Wolf Greenstein and N Majumdar contributed equally to this work)
}

Correspondence should be addressed to J Cordoba-Chacon Email jcordoba@uic.edu

\begin{abstract}
Peroxisome proliferator-activated receptor $\gamma$ (PPAR $\gamma$ ) is the target for thiazolidinones (TZDs), drugs that improve insulin sensitivity and fatty liver in humans and rodent models, related to a reduction in hepatic de novo lipogenesis (DNL). The systemic effects of TZDs are in contrast to reports suggesting hepatocyte-specific activation of PPAR $\gamma$ promotes DNL, triacylglycerol (TAG) uptake and fatty acid (FA) esterification. As these hepatocyte-specific effects of PPAR $\gamma$ could counterbalance the positive therapeutic actions of systemic delivery of TZDs, the current study used a mouse model of adult-onset, liver (hepatocyte)-specific PPAR $\gamma$ knockdown (aLivPPAR $\gamma k d$ ). This model has advantages over existing congenital knockout models, by avoiding compensatory changes related to embryonic knockdown, thus better modeling the impact of altering PPAR $\gamma$ on adult physiology, where metabolic diseases most frequently develop. The impact of aLivPPAR $\gamma \mathrm{kd}$ on hepatic gene expression and endpoints in lipid metabolism was examined after 1 or 18 weeks (Chow-fed) or after 14 weeks of low- or high-fat (HF) diet. aLivPPAR $\gamma$ kd reduced hepatic TAG content but did not impact endpoints in DNL or TAG uptake. However, aLivPPAR $\gamma$ kd reduced the expression of the FA translocase (Cd36), in 18-week Chow- and HF-fed mice, associated with increased NEFA after HF feeding. Also, aLivPPAR $\gamma$ kd dramatically reduced Mogat1 expression, that was reflected by an increase in hepatic monoacylglycerol (MAG) levels, indicative of reduced MOGAT activity. These results, coupled with previous reports, suggest that Cd36-mediated FA uptake and MAG pathway-mediated FA esterification are major targets of hepatocyte PPAR $\gamma$, where loss of this control explains in part the protection against steatosis observed after aLivPPAR $\gamma$ kd.
\end{abstract}

\section{Key Words}

- adult-onset hepatocytespecific knockdown

- Cd36

- Mogat1

- LC/MS

- diet-induced steatosis

\section{Introduction}

Non-alcoholic fatty liver disease (NAFLD) is defined as excessive accumulation of fat (steatosis) within hepatocytes that is independent of alcohol intake. NAFLD increases the risk of diabetes, non-alcoholic steatohepatitis (NASH), cirrhosis and hepatocellular carcinoma (Michelotti et al. 2013, Lade et al. 2014). Importantly, NAFLD is now 
recognized as the leading cause of chronic liver disease in the US (Younossi et al. 2011) and the third most common reason for liver transplants (Zezos \& Renner 2014). Given the negative association between NAFLD and human health, a concerted effort is being made to understand the cellular and molecular mechanisms that control hepatocyte triacylglycerol (TAG) content. It is clear that hepatocyte TAG content is dictated by the balance between fatty acid (FA) synthesis, uptake, esterification and oxidation, as well as TAG release via very-low-density lipoprotein (VLDL) (Browning \& Horton 2004). A better understanding of the mechanisms controlling these processes could help to identify individuals with higher risk of NAFLD, as well as identify novel drug targets to design therapeutic strategies that prevent or reverse NAFLD progression.

Thiazolidinones (TZDs) are synthetic agonists of the nuclear receptor, peroxisome proliferator-activated receptor $\gamma$ (PPAR $\gamma$ ) used to treat diabetes type 2 (Ahmadian et al. 2013). Treating patients with non-alcoholic steatohepatitis (an advance stage of NAFLD featured by elevated markers of liver injury and fibrosis) with TZDs reduces steatosis with variable effects on fibrosis (Belfort et al. 2006, Ratziu et al. 2008, Sanyal et al. 2010). The reduction in steatosis is associated with a reduction in hepatic de novo lipogenesis (DNL; Beysen et al. 2008). Similar to clinical studies, TZDs have also been shown to reduce hepatic fat content in rodent models (Nan et al. 2009, Gupte et al. 2010). However, in striking contrast to the global impact of TZDs: (1) hepatocyte-specific PPAR $\gamma$ expression is positively associated with fatty liver in humans (Pettinelli \& Videla 2011) and mouse models (Rahimian et al. 2001, Gavrilova et al. 2003, Matsusue et al. 2003, Inoue et al. 2005); (2) adenoviral overexpression of a PPAR $\gamma$ transgene in the liver of high-fat (HF)-fed PPAR $\alpha$ knockout or WT mice dramatically increases hepatic fat content (Yu et al. 2003, Bai et al. 2011); (3) congenital hepatocyte-specific knockout of PPAR $\gamma$ reduces hepatic fat content in mice fed a HF diet (MoranSalvador et al. 2011), as well as in mice with fatty liver due to inactivating mutations in the leptin gene (ob/ob; Matsusue et al. 2003) or lipodystrophy induced by lack of adipocyte development (AZIP; Gavrilova et al. 2003). This disconnect between the impact of systemic TZD (PPAR $\gamma$ agonist) delivery compared to the impact of hepaticspecific alterations in PPAR $\gamma$ function can be attributed to the integrated effects of PPAR $\gamma$ on multiple target tissues. Specifically, TZDs increase systemic insulin sensitivity, which in turn reduces insulin demands. These changes are associated with an increase in adiponectin production by the adipocyte. Adiponectin in turn promotes hepatic fatty acid oxidation via phosphorylation of AMPK and ACC (Yamauchi et al. 2002, Xu et al. 2003), which suppresses DNL (Xu et al. 2003). Therefore, TZD's effects on lowering steatosis are likely due to extra-hepatocyte mechanisms (Furnsinn \& Waldhausl 2002).

Although the global therapeutic effects of TZDs have been largely positive, the direct actions of PPAR $\gamma$ on the hepatocyte could serve to counterbalance these effects. Therefore, to optimize the development and use of TZDs, it is important to understand the tissue (cell)-specific impact of PPAR $\gamma$ on lipid homeostasis. With respect to the hepatocyte, studies using hepatocyte-specific PPAR $\gamma$ knockout models have led to the conclusion that PPAR $\gamma$ directly promotes hepatic fat accumulation by increasing lipid uptake, as well as promoting DNL (Gavrilova et al. 2003, Matsusue et al. 2003, 2014, Schadinger et al. 2005, Zhang et al. 2006). However, it remains unclear if the shifts in hepatic gene expression that support these conclusions are due directly to loss of hepatocyte PPAR $\gamma$ or to compensation by other hepatic genes during development and/or secondary to changes in the systemic metabolic milieu. Therefore, in the current study, we have employed a mouse model of adult-onset, hepatocyte-specific knockdown of PPAR $\gamma$ (aLivPPAR $\gamma \mathrm{kd}$ ), that is generated by treating adult (10 weeks) PPAR $\gamma^{\mathrm{f} / \mathrm{fl}}$ mice with an adeno-associated virus serotype 8 (AAV8) bearing a liver-specific thyroxine-binding globulin (TBG)-promoter driving a Cre recombinase transgene (AAV8-TBGp-Cre) vector. This model allows us to study the immediate impact of hepatocyte-specific loss of PPAR $\gamma$ in the adult liver and how this deficit influences liver function overtime under different dietary conditions. As indicated in this study and supported by accumulating evidence (Yanger et al. 2014, Ashpole et al. 2016, Shin et al. 2016), injection of AAV8-TBGp-Cre is an efficient and reproducible method to knockdown a floxed allele only in hepatocytes, independent of age.

Analysis of changes in hepatic gene expression and circulating metabolites, combined with assessment of hepatic FA composition (gas chromatography/mass spectrometry (GC/MS)) and relative levels of TAG, diacylglycerols (DAG) and monoacylglycerols (MAG) (liquid chromatography/mass spectrometry (LC/MS)), indicate that adult-onset loss of hepatocyte PPAR $\gamma$ has little direct impact on DNL, FA oxidation, lipid uptake and TAG export. However, evidence indicates that hepatic $\operatorname{PPAR} \gamma$ plays a primary role in regulating FA uptake, likely through regulating the expression of $\mathrm{Cd} 36$, and the MAG pathway, by regulating expression of Mogat1,

Published by Bioscientifica Ltd. 
which esterifies FA to MAG to form DAG. Impairment of these pathways after the loss of hepatocyte PPAR $\gamma$ may explain, in part, the protection against age- and diet-induced steatosis.

\section{Materials and methods}

\section{Animals}

All mouse studies were approved by the IACUC of the Jesse Brown VA Medical Center and performed in accordance with the Guide for the Care and Use of Laboratory Animals. PPAR $\gamma^{\mathrm{f} / \mathrm{fl}}$ (He et al. 2003) mice were purchased from Jackson Laboratories (Strain 004584, B3.129Ppargtm2Rev/J, Bar Harbor, ME) and bred as homozygotes. Animals were housed in a temperature- $\left(22-24^{\circ} \mathrm{C}\right)$ and humidity-controlled specific pathogen-free barrier facility with 12-h light/12-h darkness cycle (lights on at 06:00 h). Mice were fed a standard laboratory rodent chow diet (Formulab Diet 5008, Purina Mills, Richmond, IN, USA), unless otherwise indicated. Ten- to twelveweek-old male PPAR $\gamma^{\mathrm{fl} / \mathrm{fl}}$ littermate mice were randomized and injected in the lateral tail vein with $100 \mu \mathrm{L}$ saline containing $1.5 \times 10^{11}$ genome copies of an AAV8 bearing either a TBG-driven Cre recombinase (AAV8-TBGp-Cre, Penn Vector Core, University of Pennsylvania), which generates adult-onset hepatocyte (liver)-specific PPAR $\gamma$ knockdown mice (aLivPPAR $\gamma$ kd) or AAV8-TBGp-Null, which generates controls.

Chow-fed mice were killed in the post-absorptive state ( $4 \mathrm{~h}$ after food removal at $07: 00 \mathrm{~h})$, at 1 or 18 weeks after PPAR $\gamma$ knockdown. A separate group of PPAR $\gamma^{\mathrm{t} / \mathrm{fl}}$ mice was fed a low-fat (LF) diet with $10 \%$ kcal fat (D12450B, Research Diets, Inc. New Brunswick, NJ, USA) from weaning onward. At 10-12 weeks of age, mice were injected with either AAV8-TBGp-Cre or AAV8-TBGp-Null, and half the mice in each group switched to a nutrientmatched 60\% HF diet (D12492, Research Diets, Inc), whereas the remaining mice continued to receive a LF diet. Animals were maintained on their respective diets for 14 weeks and killed in the post-absorptive state.

Mice were killed by decapitation, and trunk blood was collected to determine blood glucose (Alphatrack2, Abbott), plasma insulin (Mercodia, Uppsala, Sweden), TAG, NEFA, cholesterol and 3 $\beta$-hydroxybutyrate (Wako Diagnostics) levels following the manufacturer's instructions. Liver and fat sub-depots were weighed. Livers were snap-frozen in liquid nitrogen and stored at $-80^{\circ} \mathrm{C}$. In a subset of mice killed 1 week after AAV8-TBGp-Null or AAV8-TBGp-Cre injection, multiple tissues were collected to assess AAV8-
TBGp-driven Cre expression. A group of 10- to 12-weekold $\mathrm{C} 57 \mathrm{Bl} / \mathrm{J}$ mice was injected with $1.5 \times 10^{11}$ genome copies of an AAV8-TBGp-EGFP (Cat \#AV-8-PV0146, Penn Vector Core, GFP as a reporter gene) and killed 1 week after to collect multiple tissues to assess GFP expression. Also, a piece of liver was fixed in $10 \%$ formalin to assess hepatocyte-specific expression of GFP.

\section{Assessment of hepatic lipids}

To assess the hepatic TAG content, neutral hepatic lipids were extracted in isopropanol and TAG measured as previously published (Cordoba-Chacon et al. 2014a).

To assess hepatic FA composition in mice fed LF and HF diets, total lipids were extracted using the Bligh and Dyer Method (Bligh \& Dyer 1959). An aliquot of extracted lipids was transmethylated to quantify specific methyl esters of FA using GC/MS, as we previously reported (Kineman et al. 2016).

LC/MS was used to assess the relative content of hepatic TAG, DAG and MAG. Briefly, hepatic homogenates were spiked with standards $(50 \mu \mathrm{g}$ trinonadecadienoin glyceride (TAG-(19:2/19:2/19:2)), $50 \mu \mathrm{g}$ dipentadecanoin glyceride (DAG-(15:0/15:0)) and 50 $\mathrm{\mu g}$ monononadecanoin glyceride (MAG-(19:0)); Nu-Chek, Waterville, MN, USA) and extracted using the Bligh and Dyer Method (Bligh \& Dyer 1959). Aliquots were dissolved in 80:19.5:0.5 parts of methanol/chloroform/ water to dilute the standards to a concentration of $0.25 \mu \mathrm{g} / \mathrm{mL}$. Samples $(10 \mu \mathrm{L})$ were injected using an Agilent 2600 UPLC into the AB Sciex 6500 Qtrap mass spectrometer (Agilent Technologies) without chromatography separation. The flow rate of mobile phase (methanol/chloroform/water 80:19.5:0.5 v/v) containing $0.1 \%$ of $\mathrm{NH}_{4} \mathrm{COOH}$ was set to $200 \mu \mathrm{L} / \mathrm{min}$. Electrospray ionization-mass spectrometry (ESI-MS) was performed in positive multiple reaction monitoring (MRM) mode for the quantitative and qualitative analysis. The spray voltage was $4.5 \mathrm{kV}$, the source temperature was set at $450^{\circ} \mathrm{C}$. Mass spectra were acquired and recorded by Analyst software (AB Sciex, version 6.1). The major neutral lipids species known to be present in the liver tissues were analyzed in MRM mode, with the transition from its ammoniated ion (Q1) to the product ion derived from the loss of its ammoniated fatty acid (Q3) (Yang \& Subbaiah 2015). Quantification of individual molecular species was performed from the relative intensities of the various species and the corresponding internal standards, respectively. Individual MRM of the internal standards was MAG-(19:0) Q1 390.4, Q3 75.1;

Published by Bioscientifica Ltd. 
DAG-(15:0/15:0) Q1 558.5, Q3 299.3; TAG(19:2/19:2/19:2) Q1 938.8, Q3 625.5.

\section{Gene expression analysis}

Hepatic and adipose tissue RNA was extracted using TRIzol Reagent (Life Technologies) and treated with RQ1 RNase-free DNase (Promega). DNA-free RNA was transcribed, and qPCR was performed as previously published (Cordoba-Chacon et al. 2014a, Kineman et al. 2016). qPCR primer sequences for PPAR $\gamma$, carnitine palmitoyltransferase $1 \alpha(\operatorname{Cpt} 1 \alpha)$, adipose triglyceride lipase (Atgl), hormone-sensitive lipase (Hsl), sterol response element-binding protein 1c (Srebp1c), acetylCoA carboxylase 1 (Acc1), fatty acid synthase (Fasn), fatty acid elongase (Elovl6), stearoyl-CoA desaturase 1 (Scd1), fatty acid translocase (Cd36), glycerol phosphate acyltransferase (Gpat1), monoacylglycerol acyltransferase 1 (Mogat1), Cre recombinase, GFP, cyclophilin A, $\beta$-actin and hypoxanthine-guanine phosphoribosyltransferase were previously published (Cordoba-Chacon et al. 2014a, 2015a, Kineman et al. 2016). Primer sequences for PPAR $\alpha$ (NM_011144): Se: GGGAAAGACCAGCAACAACC, As: GC AGTGGAAGAATCGGACCT; acyl-CoA synthetase long-chain family member 1 (Acsl1, NM_007981): Se: GAGGGTGAGGTGTGTGTGAAA, As: CCGTGTGTAACC AGCCATCT; hepatic nuclear factor $4 \alpha$ (Hnf $4 \alpha$, NM_008261.3): Se: ACATTCGGGCAAAGAAGATTG, As: ACCTGGTCATCCAGAAGGAGTT; PPAR $\gamma$ co-activator $1 \alpha$; (Pgc1 $\alpha, \quad$ NM_008904.2): Se: TTCCCGATCACCATATT CCA, As: TTCATCCCTCTTGAGCCTTTC; Cyp4a10 (NM_010011.3): Se: CCACTGATTCTGTTGTGGAGC, As: CATTAGAAGAGAGGGGATGAGGA; monoacylglycerol lipase (Mgll, NM_001166251.1): Se: GTGGAATGCAAAA GCCAAGA, As: AGCTCATCATAACGGCCACA; apolipoprotein B (ApoB, NM_009693.2): Se: AGCCCAGCACTGACTGACTT, As: GAAGCCTTGGGCA CATTG; microsomal triglyceride transfer protein (Mttp, NM_001163457.1): Se: CAGTGGATGCCTCTTTTGTG, As: GTCTCGAATTGCCTGAGTGG; hepatic lipase (Hl, NM_008280.2): Se: TTTTCCTGGTGTTCTGCATCT, As: CA GGCGATCGTTTTCATCTT; low-density lipoprotein lipase receptor (Ldlr, NM_001252658.1): Se: TGTCA CCTGTCAGTCCAATCAA, As: TCAGAGCCATCTAGGCAA TCTC; very-low-density lipoprotein receptor (Vldlr, NM_013703.2): Se: GTGCAAGGCAGTAGGCAAAG, As: GCTGAGATCAGCCCAAAACA; lipoprotein-related protein 1 (Lrp1, NM_008512.2): Se: ACACACGCCAACTG TACCAA, As: TGACATTCGGGTCACAAACA; monoacylglycerol acyltransferase 2 (Mogat2,
NM_146035.2): Se: TGTGAAAACTTGGAAATCGACA, As: CAGTCTCCAGCATGAAAAATCC; diacylglycerol acyltransferase 1 (Dgat1, NM_010046.2): Se: AGCTGTGGCC TTACTGGTTG, As: AGCAGCCCCACTGACCTT.

\section{Western blot}

Livers were homogenized in extraction buffer $\mathrm{pH} 7.5$, $50 \mathrm{mM}$ HEPES, $2 \mathrm{mM}$ EGTA, $2 \mathrm{mM}$ EDTA, $130 \mathrm{mM} \mathrm{NaCl}$, $10 \mathrm{mM} \mathrm{NaF}, 20 \mathrm{mM}$-glycerophosphate, $2 \mathrm{mM}$ sodium pyrophosphate, $1 \mathrm{mM}$ sodium vanadate, $0.5 \mathrm{mM}$ PMSF, $0.1 \%$ nonidet P-40, $2 \mathrm{mM}$ benzamidine, $1 \mathrm{mM}$ TLCK, $10 \mu \mathrm{g} / \mathrm{mL}$ leupeptin, $10 \%$ glycerol, with protease inhibitors (Complete, Roche), followed by sonication for $10 \mathrm{~s}$. Protein concentration was determined using Bradford reagent (Bio-Rad Laboratories). 100 $\mu$ g of denatured proteins were separated by SDS-PAGE (Mini-PROTEAN TGX Gels 10\%, Bio-Rad Laboratories) and transferred to nitrocellulose membranes. Membranes were blocked with 5\% nonfat, dry milk in Tris-buffered saline with $0.05 \%$ Tween-20 for $1 \mathrm{~h}$ at $25^{\circ} \mathrm{C}$, and then incubated with primary antibodies overnight at $4^{\circ} \mathrm{C}$ (Rabbit anti-human PPAR $\gamma$ mAb (C26H12), 1/500; Rabbit anti-human Histone H3 mAb (D1H2), 1/1000 (Cell Signaling Technology)), washed and incubated with secondary antibodies for $2 \mathrm{~h}$ at $25^{\circ} \mathrm{C}$ (Goat AntiRabbit IgG (H+L)-HRP Conjugate, 1/2000 (Bio-Rad Laboratories)). After washing, SuperSignal WestFemto Maximum Sensitivity Substrate (Thermo Scientific) was added and the light signal was detected and analyzed using a C-Digit Blot Scanner and Image Studio Lite Ver 3.1 (Li-Cor Biosciences, Lincoln, NE, USA).

\section{Immunohistochemistry}

Livers were fixed in formalin and paraffin embedded. $5 \mu \mathrm{m}$ sections were deparaffinized, hydrated in gradedethanol/water solutions and then treated with $10 \mathrm{mM}$ citrate buffer at $125^{\circ} \mathrm{C}$ for $5^{\prime}$ (GFP, desmin and F4/80 staining) followed by $0.05 \%$ porcine trypsin in Trisbuffered solution (TBS) for $10 \mathrm{~min}$ at $37^{\circ} \mathrm{C}$ (F4/80 staining only). Samples were blocked in TBS-containing $1.5 \%$ goat serum and $0.01 \%$ Tween-20 for $20^{\prime}$, and sections were incubated $\left(4^{\circ} \mathrm{C}\right.$ overnight in TBS $0.01 \%$ Tween-20) with mouse anti-GFP, 1:100 Cell Signaling \#2955; rabbit anti-desmin, 1:50 Cell Signaling \#5332; rat anti-F4/80 1:50 eBiosciences (San Diego, CA, USA) \#14-4801-82. Secondary antibodies (1:500 in blocking buffer): goat anti-rabbit IgG Alexa Fluor594 Cell Signaling \#8889 (for desmin staining), goat anti-mouse IgG Alexa Fluor594

Published by Bioscientifica Ltd. 
Cell Signaling \#8890 and goat anti-mouse IgG Fluor488 Cell Signaling \#4408 (for GFP stainings), goat anti-rat IgG Alexa Fluor488 Cell Signaling \#4416 (for F4/80 staining). Sections were mounted with Fluoroshield with DAPI (Sigma-Aldrich) and immunofluorescence was detected using a Olympus BX43 microscope (Olympus). Images were recorded using Olympus CellSens software (Olympus) and processed using Image (NIH) and CellSens (Olympus).

\section{Statistics}

Student's $t$-tests were performed to analyze the effect of AAV8-TBGp-Cre on PPAR $\gamma$ expression in liver, epididymal fat (eWAT) and inguinal fat (iWAT) (Fig. 1G). 2-Way ANOVA, followed by Bonferroni's post hoc analysis, was used to determine the effect of aLivPPAR $\gamma$ kd with age or the effect of aLivPPARkd with diet. $P$ values less than 0.05 were considered significant.
All statistical analyses were performed using GraphPad Prism 5 (GraphPad Software).

\section{Results \\ Validation of hepatocyte-specific expression of TBGp-driven transgene after AAV8 injection}

Hepatocyte specificity expression of transgenes delivered by AAV8 and driven by TBG was confirmed using an AAV8-TGBp-EGFP reporter (Fig. 1A, B, C, D and E) that led to GFP-positive staining only in hepatocytes and not in other cell types, including vascular endothelial cells, connective tissue surrounding vessels, cholangiocytes of bile ducts (Fig. 1A and B), hepatic stellate cells (HSC; stained positive (red) for desmin (Fig. 1C)) and macrophages, (stained positive (red) F4/80 (Fig. 1D)). AAV8-TBGp-driven GFP and Cre expression was detected in hepatic but not in extrahepatic tissues
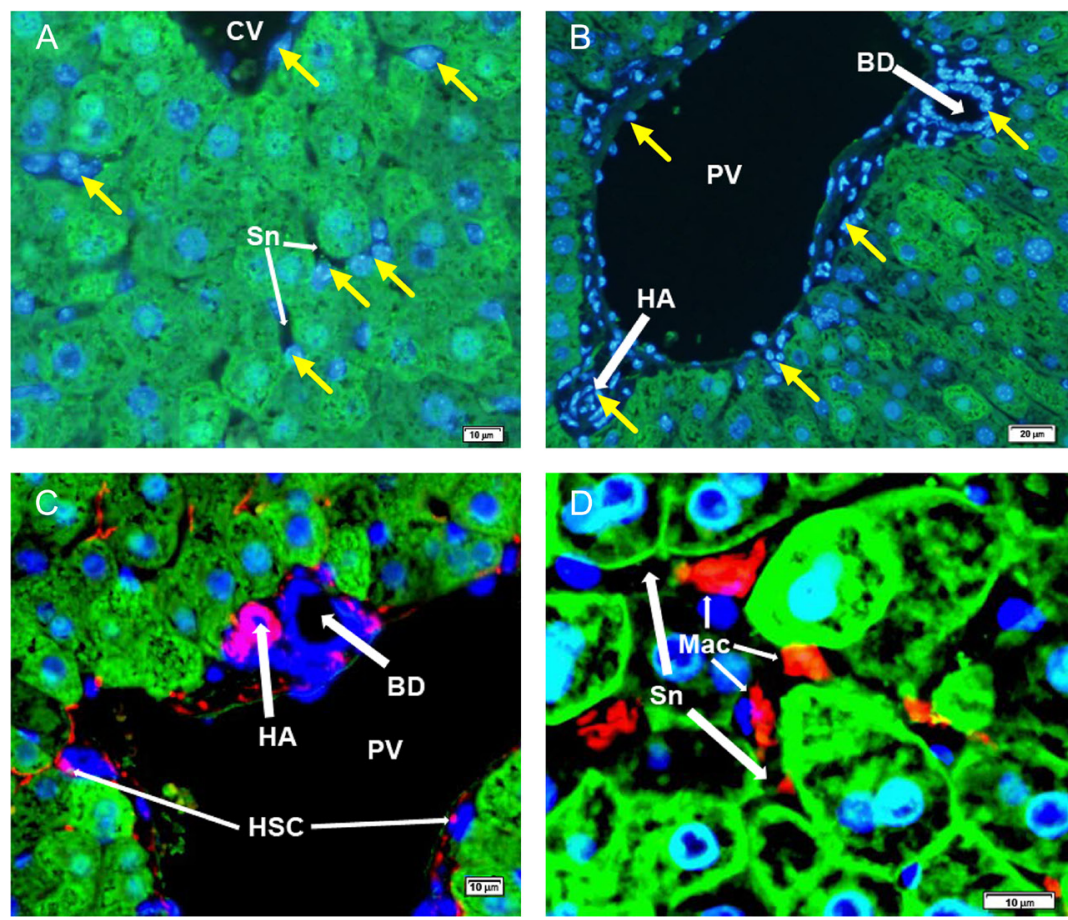
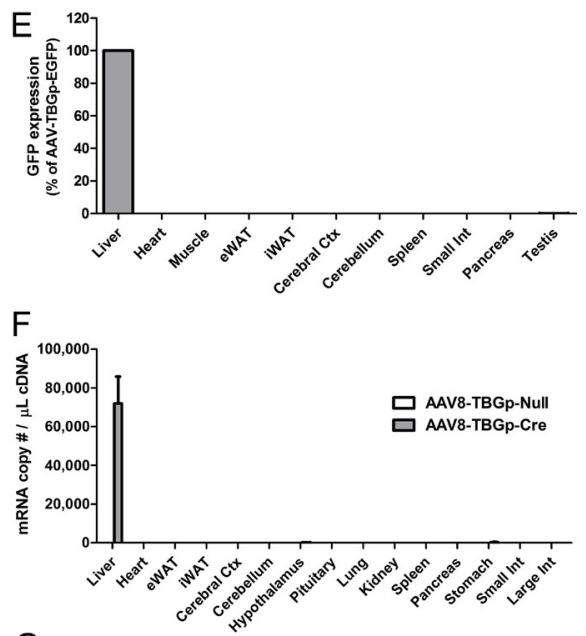

G

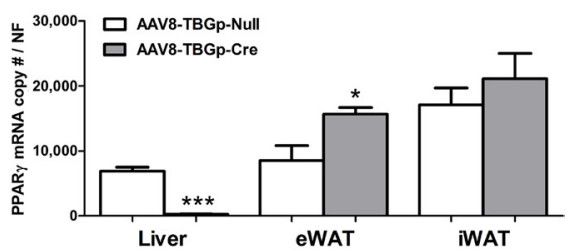

\section{Figure 1}

Hepatocyte specificity expression of AAV8-TBGp-driven transgene. Hepatocyte-specific expression of GFP in AAV8-TBGp-EGFP-injected wild-type mice (green, A and B). GFP expression was absent in non-hepatocyte cells (yellow arrows) in sinusoids (Sn), central vein (CV), portal vein (PV), bile duct (BD) or artery (HA). TBGp-GFP was not expressed in hepatic stellate cells (HSC, desmin +, red, C) or macrophages (Mac, F4/80+, red, D). Sections were counterstained with DAPI (blue nuclei, A, B, C and D). Hepatic GFP (E) and Cre (F) expression was detected only in liver extracts of AAV8-TBGp-EGFP- and AAV8-TBGp-Creinjected mice, respectively. To confirm the hepatocyte-specific activity of Cre recombinase, PPAR flff $^{\text {flf }}$ mice were injected with AAV8-TBGp-Cre and expression of PPAR $\gamma$ was reduced in hepatic extracts but not adipose tissue (G). Ctx, cortex; eWAT, epididymal fat; Int, intestine; iWAT, inguinal fat. Asterisks indicate the difference between AAV8-TBGp-Cre-injected mice as compared to AAV8-TBGp-Null mice. ${ }^{*} P<0.05 ; * * * P<0.0001 . n=3-6$ mice/group.

http://joe.endocrinology-journals.org DOI: $10.1530 / J O E-16-0447$ (c) 2017 Society for Endocrinology Printed in Great Britain
Published by Bioscientifica Ltd 
A AAV8-TBGP-Null - AAV8-TBGP-Cre

\begin{tabular}{|cccc|}
\hline Age (weeks) : 0 & AAV-injection & \\
\hline PPAR $\gamma^{\text {flfth }}$ mice & 10 & 11 & 28 \\
\hline No phenotype - Chow diet & & \multicolumn{2}{c|}{ Control } \\
\hline Knockdown (weeks): & 0 & 1 & 18 \\
\hline
\end{tabular}

\section{B PPAR $Y$ MRNA}

\section{PPAR y protein}
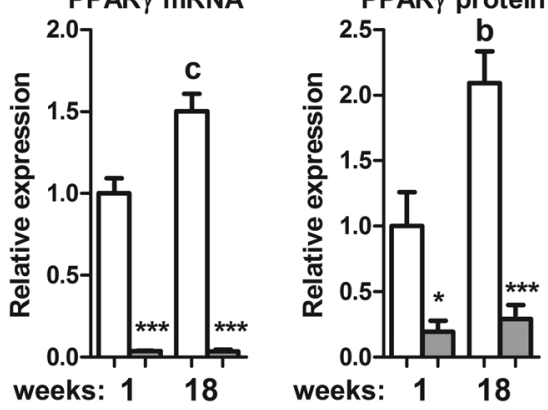

weeks: 118

weeks: 118
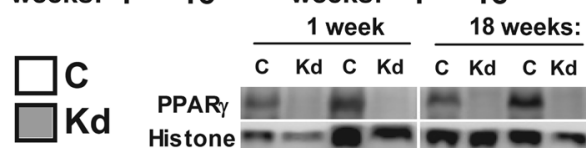

PPAR $\gamma$

C Kd C Kd $\mathrm{C} \mathrm{Kd} \mathrm{C} \mathrm{Kd}$

Histone

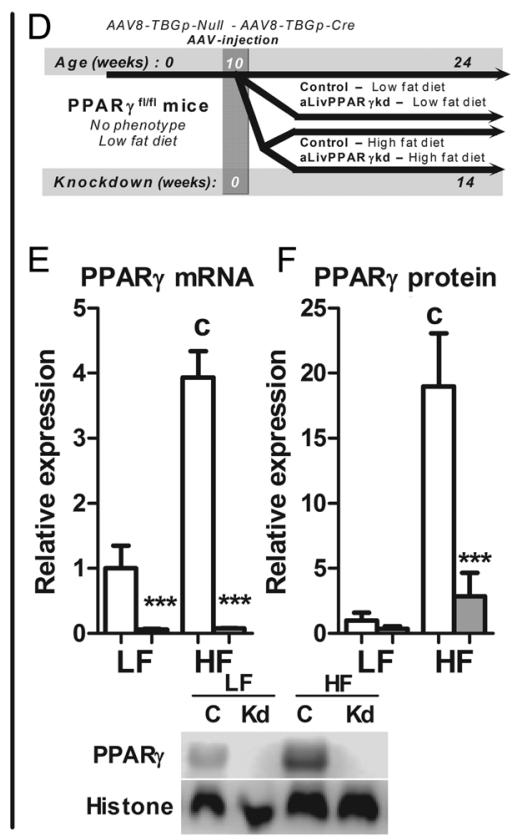

Figure 2

Adult-onset hepatocyte-specific PPAR $\gamma$ knockdown (aLivPPAR $\gamma$ kd) in chow-fed mice (A, B and C) and diet-induced obese mice (D, E and F). (A) PPAR $\gamma^{f \mid l f l}$ mice were injected at 10 weeks of age with $1.5 * 10^{11} \mathrm{GC}$ AAV8-TBGp-Null (C, open columns) or $1.5 * 10^{11} \mathrm{GC}$ AAV8-TBGp-Cre (Kd, shaded columns) via lateral tail vein and killed 1 or 18 weeks after. (B) Hepatic PPAR $\gamma$ mRNA and (C) protein expression of 1 week and 18 weeks aLivPPAR $\gamma$ kd and their littermate control mice. Representative image of the western blot for hepatic PPAR $\gamma$ and Histone (as loading control). Of note, nuclear protein variability within total hepatic extracts (assessed by Histone) alters the amount of PPAR $\gamma$ protein detected. $n=4-5$ mice/group. (D) LF-fed PPAR $\gamma^{f l / f l}$ mice were injected at 10 weeks as described above and immediately half of the mice were fed a high-fat diet ( $\mathrm{HF}, 60 \% \mathrm{kcal}$ from fat) to induce liver steatosis, whereas the rest were maintained on a low-fat diet (LF, $10 \% \mathrm{kcal}$ from fat). Mice were killed 14 weeks after. (E) Hepatic PPAR $\mathrm{mRNA}$ and (F) protein expression of 14 weeks LF- and HF-fed aLivPPAR $\gamma \mathrm{kd}$ and their littermate controls. Representative images of the western blot for hepatic PPAR $\gamma$ and Histone (as loading control). Asterisks indicate the differences between $\mathrm{C}$ and $\mathrm{Kd} .{ }^{*} P<0.05 ; * * * P<0.0001$. Letters indicate the differences between 1 week and 18 weeks or LF- and HF-fed mice within group. $\mathrm{b} P<0.01 ; c P<0.0001 . n=5-6$ mice/group.

(Fig. 1E and F). Expression of PPAR $\gamma$ was reduced in liver but not in adipose tissue (Fig. 1G). Interestingly, a modest increase of PPAR $\gamma$ expression was detected in eWAT of aLivPPAR $\gamma \mathrm{kd}$ mice.

\section{Effects of hepatocyte-specific PPAR $\gamma$ knockdown on metabolic endpoints in adult mice (aLivPPAR $\gamma \mathrm{kd}$ )}

After 1 and 18 weeks of chow diet AAV8-TBGpCre injection resulted in a clear knockdown of hepatocyte PPAR $\gamma$ mRNA and protein at 1 week after injection that persisted after 18 weeks of AAV8 injection (Fig. 2A, B and C). Mouse PPAR $\gamma$ gene produces two isoforms PPAR $\gamma 1$ and PPAR $\gamma 2$ (NM_001127330.2 and NM_0111463). Three mRNA variants are described for PPAR 1 (variant 1: NM_001127330.2; variant 3: NM_001308352.1; variant 4: NM_001308354.1), but all encode for the same protein (isoform 1). In PPAR $\gamma^{\mathrm{f} / \mathrm{ll}}$ mice two exons, previously described as exons 1 and 2 (He et al. 2003), are flanked by loxP sites. These exons span 227 and $169 \mathrm{bp}$ respectively are located within the CDS of each variant and the GPCR primers employed in this study are placed in these two exons. Therefore, the qPCR result of PPAR $\gamma$ gene expression accounts for all variants and thereby the western blot results account for both isoforms. Of note, hepatic PPAR $\gamma$ mRNA levels modestly, but significantly, increased with age in control but not aLivPPAR $\gamma \mathrm{kd}$ mice (Fig. 2B and C).

To assess if hepatic lipid metabolism was altered in chow-fed aLivPPAR $\gamma \mathrm{kd}$ mice, we measured whole body, liver and adipose tissue (unilateral epididymal, inguinal and retroperitoneal fat depots) weights, hepatic TAG levels, as well as circulating blood glucose, plasma insulin, ketones, TAG, NEFA and cholesterol (Table 1). For the majority of endpoints examined, aLivPPAR $\gamma \mathrm{kd}$ had no effect in either age group. However, there was an overall inhibitory effect of aLivPPAR $\gamma$ kd on hepatic TAG levels $(P=0.0185)$, indicating hepatic PPAR $\gamma$ plays a role in hepatic lipid accumulation, even under standard feeding conditions. 
Table 1 Impact of aLivPPAR $\gamma k d$ on body, liver and fat depot (sum of the unilateral epididymal, inguinal and retroperitoneal fat depot) weight, hepatic TAG levels and circulating metabolic endpoints (blood glucose, plasma insulin, ketones, TAG, NEFA and NEFA), in chow-fed (top, 1 week and 18 weeks) and LF/HF-fed (bottom, 14 weeks) aLivPPAR $\gamma$ kd mice and their littermate controls.

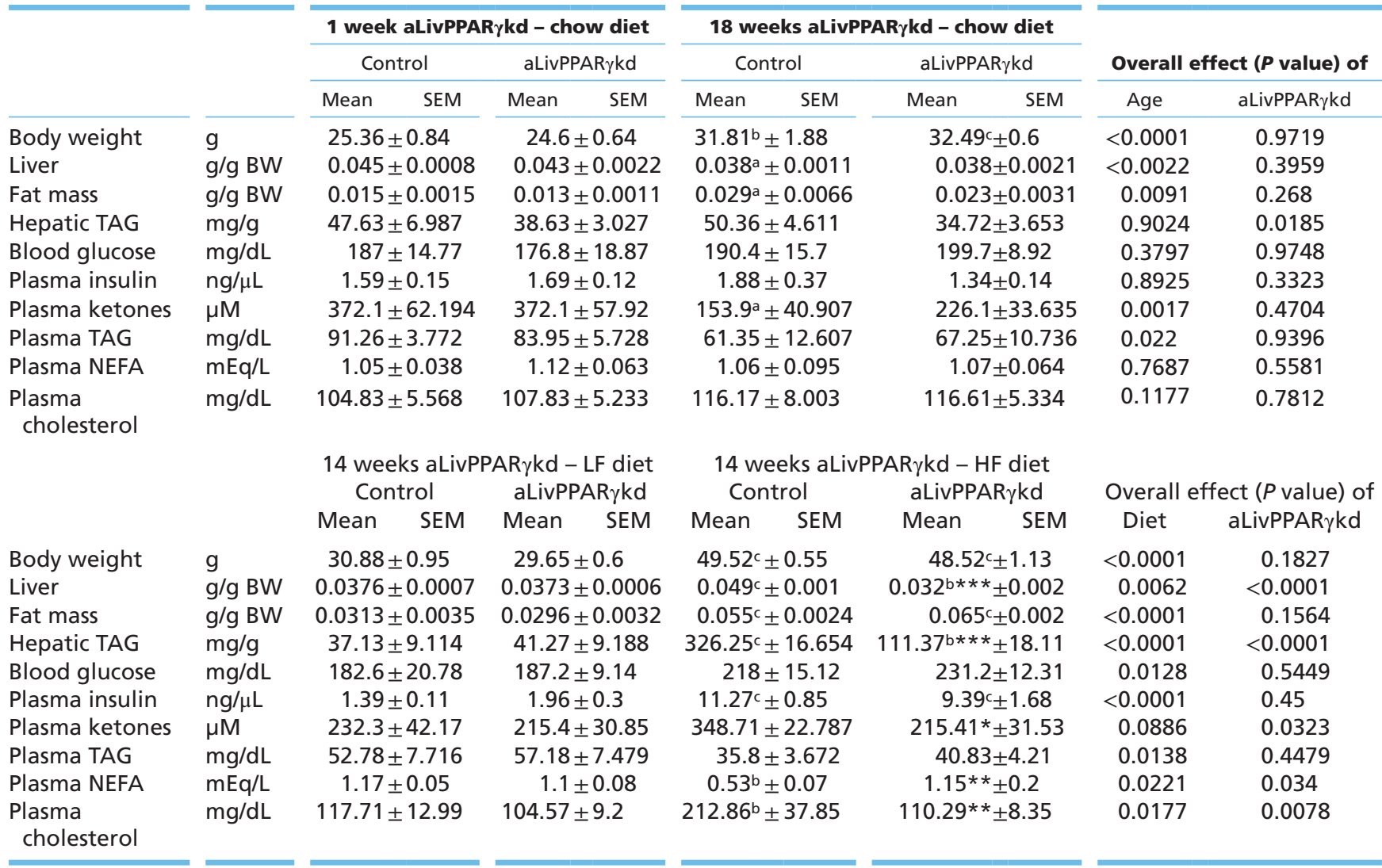

Superscript letters indicate differences between 1 week and 18 weeks or LF- and HF-fed mice within group. a $P<0.05$; b $P<0.01 ; c P<0.0001$. Asterisks indicate the differences between control and aLivPPAR $\gamma \mathrm{kd}$ mice. ${ }^{*} P<0.05 ; * * P<0.01 ; * * * P<0.0001$. $n=4-6$ mice/group.

After 14 weeks of LF or HF diet To further explore if hepatic lipid accumulation induced by excess dietary fat intake is altered by aLivPPAR $\gamma \mathrm{kd}$, we fed a HF- or a nutrient-matched LF control diet to aLivPPAR $\gamma \mathrm{kd}$ mice and their littermate controls. After 14 weeks of either LF or HF feeding (Fig. 2D) hepatic PPAR $\gamma$ mRNA/protein expression remained suppressed in aLivPPAR $\gamma \mathrm{kd}$ mice, compared to controls (Fig. 2E and F).

Consistent with previous reports (Inoue et al. 2005, Moran-Salvador et al. 2011, Yamazaki et al. 2011), $\mathrm{HF}$ feeding in control mice increased hepatic PPAR $\gamma$ expression, compared to those fed a LF diet (Fig. 2E and F). Also, in control mice, HF feeding increased body, liver and fat mass weight and elevated hepatic TAG content and plasma glucose, insulin and cholesterol levels, but plasma TAG and NEFA were reduced (Table 1). Although TAG and NEFA are reported to be elevated in HF-fed mice after an overnight fast, in the post-absorptive state (4-h fasted mice at 11:00 h), TAG and NEFA levels are reported to be reduced (Guo et al. 2009, Obrowsky et al. 2013, CordobaChacon et al. 2014b, 2015b, Horakova et al. 2016), likely due to elevated insulin levels under these conditions.

aLivPPAR $\gamma k d$, in LF-fed mice, did not impact any of the metabolic endpoints examined (Table 1), including food intake (data not shown). However, HF-fed aLivPPAR $\gamma$ kd mice showed reduced relative liver weight, and this was associated with a reduced hepatic TAG content (Table 1). Despite reduced hepatic TAG levels, there were no differences in post-absorptive blood glucose, plasma insulin and TAG levels in HF-fed aLivPPAR $\gamma$ kd mice, compared to diet-matched controls (Table 1). However, normal glucose and insulin levels in the post-absorptive mouse may not be indicative of the whole-body glucose homeostasis, which requires dynamic evaluation by glucose and insulin tolerance tests. Of note, plasma ketones and cholesterol were reduced in HF-fed aLivPPAR $\gamma$ kd mice, whereas plasma NEFAs were increased as compared to HF-fed control littermates (Table 1).

Published by Bioscientifica Ltd. 

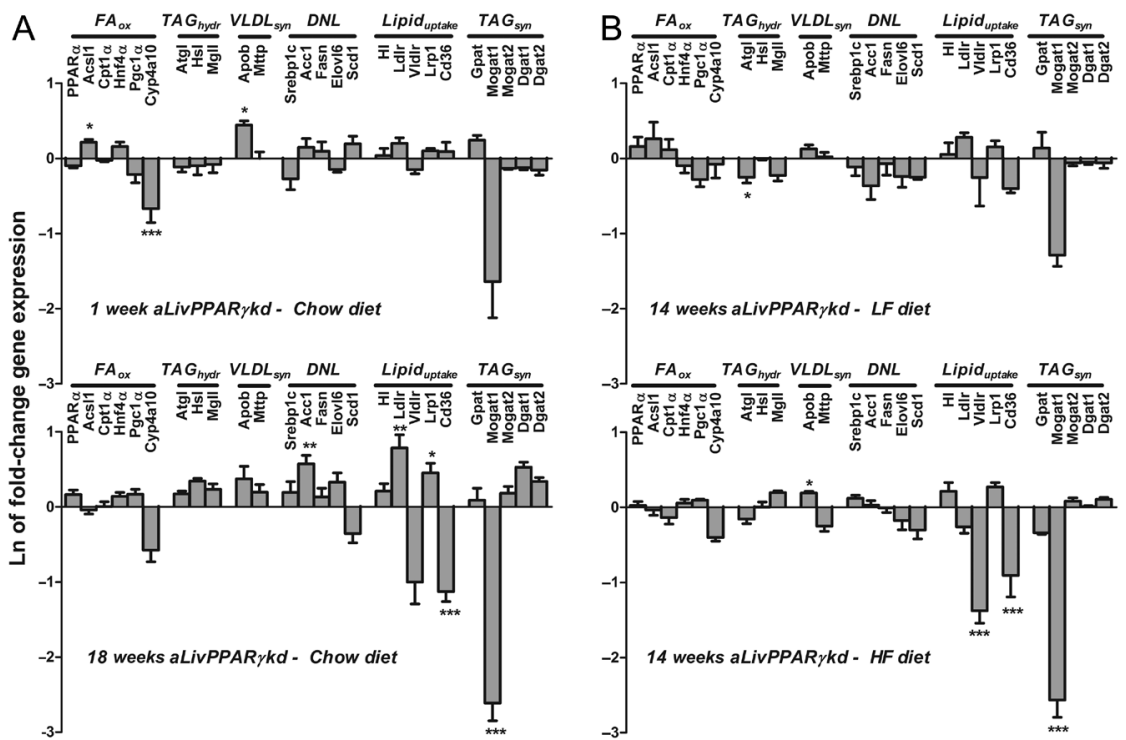

\section{Figure 3}

Impact of aLivPPAR $\gamma \mathrm{kd}$ on hepatic gene expression of molecular mechanisms controlling hepatic TAG levels. (A) 1-week (top) and 18-week (bottom) chow-fed and (B) 14-week LF-fed (top) and HF-fed (bottom) aLivPPAR $\gamma$ kd-induced regulation of hepatic gene expression. Graphs represent the natural logarithm of the relative change in the gene expression of aLivPPAR $\gamma \mathrm{kd}$ mice as compared to their littermates controls (set at $0, x$-axis), within age (A) or diet (B). Absolute values are included in Supplementary Table 1A and B. Asterisks show significant changes between C and aLivPPAR $\gamma k$ d within age (A) or diet (B). ${ }^{*} P<0.05 ; * * P<0.01 ; * * * P<0.0001$. Livers were collected at 11:00 h (4h after food removal). DNL, de novo lipogenesis; $F A_{o x}$, fatty acid oxidation; TAG hydr TAG hydrolysis; $V_{L D L}$ syn, VLDL synthesis; $T_{A G}$ syn, $T A G$ synthesis. Selected genes of these metabolic pathways represented in Fig. 3: peroxisome proliferator-activated receptor $\alpha$ (PPAR $\alpha$ ), acyl-CoA synthetase long-chain family member 1 (Acsl1), carnitine palmitoyltransferase 1 $\alpha$ (Cpt1 $\alpha$ ), hepatic nuclear factor $4 \alpha(\mathrm{Hnf} 4 \alpha)$, PPAR $\gamma$ co-activator $1 \alpha(\mathrm{Pgc} 1 \alpha)$, Cyp4a10, adipose triglyceride lipase (Atgl), hormone-sensitive lipase (Hsl), monoacylglycerol lipase (Mgll), apolipoprotein $B(A p o B)$, microsomal triglyceride transfer protein (Mttp), sterol response element-binding protein 1c (Srebp1C), acetyl-CoA carboxylase 1 (Acc1), fatty acid synthase (Fasn), fatty acid elongase (Elovl6), stearoyl-CoA desaturase 1 (Scd1), hepatic lipase (HI), low-density lipoprotein lipase receptor (Ldlr), very-low-density lipoprotein receptor (VIdlr), lipoprotein-related protein 1 (Lrp1), fatty acid translocase (Cd36), glycerol phosphate acyltransferase (Gpat1), monoacylglycerol acyltransferase 1 or 2 (Mogat1/2), diacylglycerolacyltransferase 1/2 (Dgat1/2).

\section{Association between aLivPPAR $\gamma$ kd-mediated alterations in hepatic gene expression and metabolic endpoints}

It has been previously reported that congenital liverspecific knockout of PPAR $\gamma$ alters the expression of a number of genes related to the regulation of hepatic TAG levels (Gavrilova et al. 2003, Matsusue et al. 2003, Moran-Salvador et al. 2011). However, from these studies, it is difficult to determine which changes may be due to the direct actions of hepatocyte PPAR $\gamma$ and which may be altered by secondary changes that occur overtime. Therefore, qPCR was used to screen changes in expression of key genes related to fatty acid oxidation, intrahepatic TAG hydrolysis, hepatic TAG export, DNL, hepatic lipid uptake and TAG synthesis, in liver samples from chowfed ( 1 and 18 weeks after aLivPPAR $\gamma$ kd, Fig. 3A) and LFand HF-fed (14 weeks after aLivPPAR $\gamma$ kd, Fig. 3B) mice. The data shown in Fig. 3 are expressed as fold-change in hepatic gene expression in aLivPPAR $\gamma \mathrm{kd}$ mice, compared to PPAR $\gamma$-intact controls (set at 0), within age and diet, whereas Supplementary Table 1A and B (see section on supplementary data given at the end of this article) provides absolute values. There were small, but significant changes in the expression of a number of genes in aLivPPAR $\gamma \mathrm{kd}$ mice, compared to PPAR $\gamma$-intact controls within specific groups. However, collective examination of this data set provides insight into which genes (pathways) are major targets of PPAR $\gamma$, that could explain why aLivPPAR $\gamma \mathrm{kd}$ protects against hepatic fat accumulation.

De movo lipogenesis Although experimental evidence suggests that hepatocyte PPAR $\gamma$ promotes liver fat accumulation by regulating the expression of genes important for DNL (Matsusue et al. 2003, 2014), aLivPPAR $\gamma \mathrm{kd}$ did not significantly reduce the expression of DNL genes (Srebp1c, Acc1, Fasn, Elovl6, Scd1) across age or diet. However, we could not exclude the fact aLivPPAR $\gamma \mathrm{kd}$ could indirectly mediate the activity of DNL enzymes, independent of changes in gene expression. Therefore, to estimate the impact of aLivPPAR $\gamma \mathrm{kd}$ on hepatic DNL, we used GC/MS to measure FA composition in livers of mice fed either a LF or HF diet. Supplementary Table 2 provides 

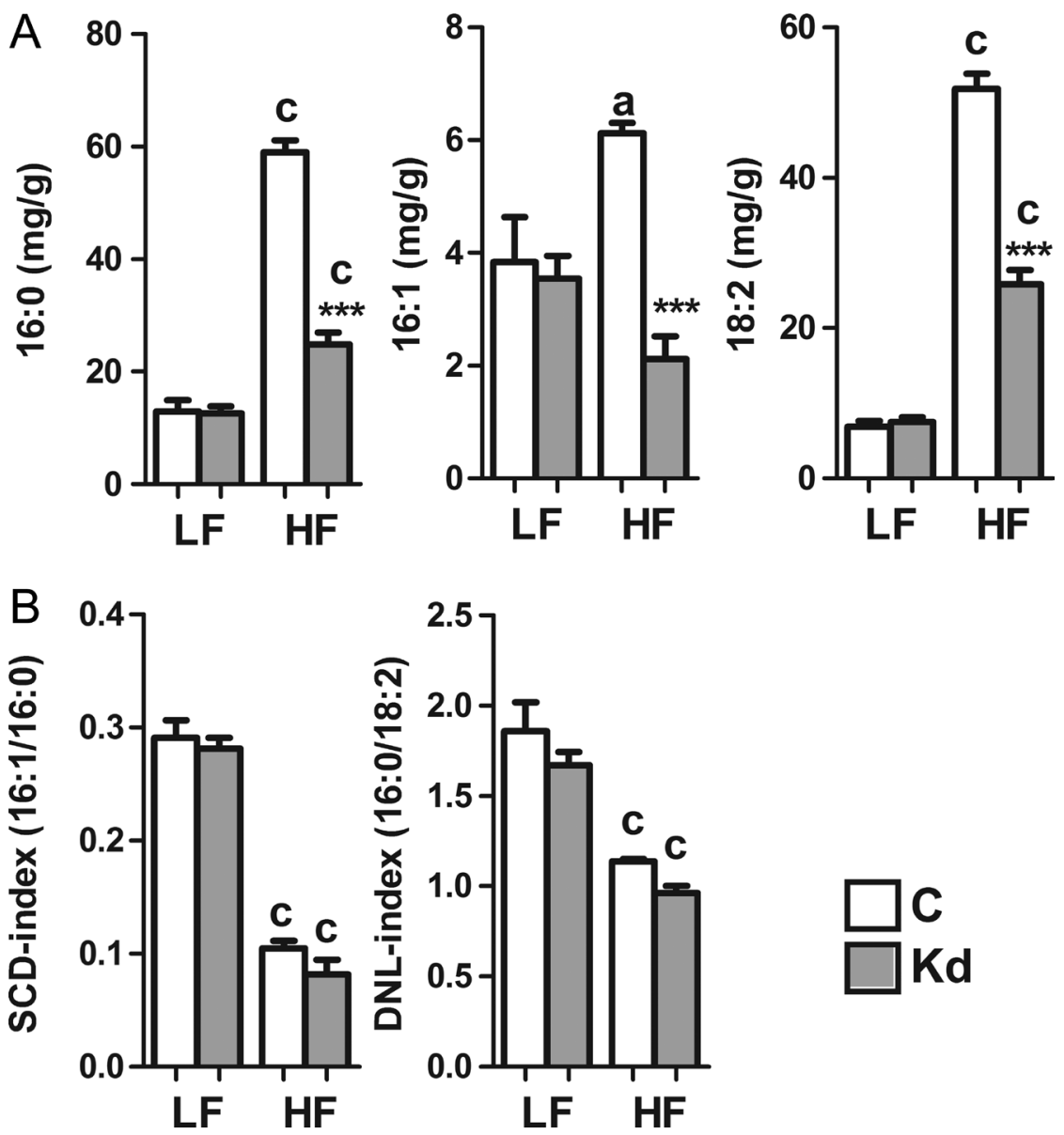

Figure 4

aLivPPAR $\gamma$ kd reduces HF diet-induced FA levels, but has little impact on FA indices of DNL. (A) Hepatic FA levels of 16:0, palmitate; 16:1, palmitoleate; and 18:2, linoleate levels and (B) hepatic FA ratios indicative of DNL include the SCD index (16:1/16:0) and the DNL index (16:0/18:2), where control (open columns, C) and aLivPPAR $\gamma$ kd (closed columns, Kd) mice were fed a LF or a HF diet for 14 weeks. Asterisks indicate differences between $\mathrm{C}$ and $\mathrm{Kd}$. ${ }^{*} * * P<0.0001$. Letters indicate differences between LF- and HF-fed mice within group. a $P<0.05 ; c P<0.0001$. $n=4-6$ mice/group.

data for all FA detected, whereas Fig. 4A shows absolute levels of palmitic acid (16:0), palmitoleic acid (16:1(n-7)) and linoleic acid (18:2(n-6)). The absolute levels of these FAs were significantly reduced in HF-fed aLivPPAR $\gamma \mathrm{kd}$ mice as compared to HF-fed controls, consistent with the reduction in hepatic TAG content. Specific ratios of these FA (Fig. 4B) have been shown to be indicative of DNL (SCD-1 index 16:1/16:0) and DNL index, 16:0/18:2 (Sevastianova et al. 2012, Silbernagel et al. 2012, Lee et al. 2015, Kineman et al. 2016). As previously reported, HF diet reduces the rate of DNL (Duarte et al. 2014) and expression of DNL proteins (Benard et al. 2016), as reflected by significant reduction in both the SCD-1 and DNL index, as well as the reduction in DNL gene expression (Acc1, Fasn, Elovl6 and Scd1; Supplementary Table 1B). Independent of diet, loss of hepatocyte PPAR $\gamma$ did not influence these indices (Fig. 4B). Taken together, these results suggest that hepatic PPAR $\gamma$ plays a minimal role in directly regulating hepatic DNL.

Hepatic TAG export, FA oxidation and lipid uptake A reduction in hepatic fat content observed in aLivPPAR $\gamma \mathrm{kd}$ mice could be due to an increased rate

of hepatic VLDL production or a decreased rate of TAG lipoprotein clearance. However, examination of genes critical for these processes were not consistently altered by aLivPPAR $\gamma \mathrm{kd}$ (Fig. 3) and circulating TAG in aLivPPAR $\gamma \mathrm{kd}$ did not differ from PPAR $\gamma$-intact controls, within age and diet group (Table 1). It could also be possible that the reduced TAG content observed in livers of aLivPPAR $\gamma \mathrm{kd}$ mice is due to an increase in intrahepatic TAG hydrolysis and FA oxidation. However, the fact that the expressions of Atgl, Hsl, Mgll, PPAR $\alpha$, Acsl1, Cpt1 $\alpha$, Hnf $4 \alpha$, Pgc1 $\alpha$ and Cyp4a10 were not increased across groups (Fig. 3), whereas HF-aLivPPAR $\gamma \mathrm{kd}$ mice exhibited a decrease in plasma ketones (Table 1), suggests that hepatic FA oxidation is actually reduced. It is possible that this reduction in FA oxidation/ketogenesis is secondary to a reduction in intrahepatic FA availability due to a reduction in FA uptake as aLivPPAR $\gamma \mathrm{kd}$ reduced the expression of hepatic Cd36 (FA translocase), where this was associated with an increase in circulating NEFA in HF-fed mice (Table 1). In fact, Cd36 has been previously shown to be a PPARy target gene (Tontonoz et al. 1998). However, it should be noted that a significant reduction in Cd36 was not 

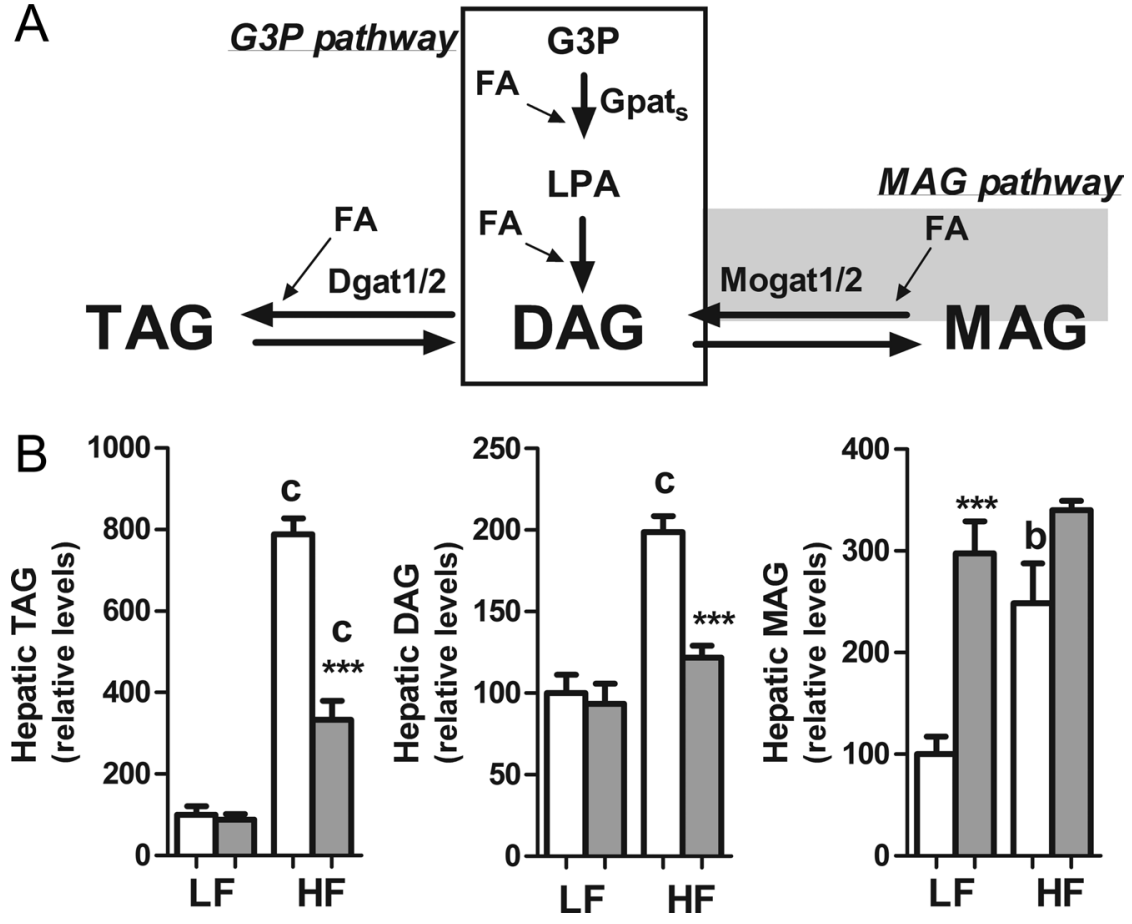

Figure 5

aLivPPAR $\gamma$ kd reduces $\mathrm{HF}$ diet-induced hepatic TAG and DAG levels, whereas increasing MAG levels, independent of diet, indicative of impaired hepatic MAG pathway activity in aLivPPAR $\gamma$ kd mice. (A) Schematic representation of acylglycerol synthesis by glycerol-3-phosphate (G3P) pathway that produces DAG by subsequent re-esterification of FA in G3P and lysophosphatidic acid (LPA) or by monoacylglycerol (MAG) pathway that produces DAG after re-esterification of FA in MAG. (B) Relative hepatic TAG, DAG and MAG levels assessed by liquid chromatography/mass spectrometry (LC/MS) in control (open columns) and aLivPPAR $\gamma$ kd (close columns) mice. TAG, DAG and MAG are shown as relative values of LF-fed controls. Asterisks indicate differences between control and aLivPPAR $\gamma \mathrm{kd}$. $* * * P<0.0001$. Letters indicate differences between LF- and HF-fed mice within group. ${ }^{b} P<0.01 ; c P<0.0001$. $n=5-6$ mice/group.

observed in aLivPPAR $\gamma$ kd after 1 week of knockdown, or in LF-fed mice, suggesting that under these conditions, the low level of PPAR $\gamma$ is not sufficient to maintain Cd36 expression or that the full expression requires additional factors that are activated with age or diet, such as LXR and PXR (Zhou et al. 2008).

TAG synthesis TAG, DAG and MAG are generated by esterification of newly synthetized FA or extrahepatic FA into acylglycerol backbones, as illustrated in Fig. 5A. In the liver, it is thought that the primary source of TAG is via the glycerol-3-phosphate (G3P) pathway, that generates DAG (Coleman \& Mashek 2011, Mashek 2013), which serves as a substrate of DAG transferases 1 and 2 (Dgat1/2). However, it is becoming evident that the MAG pathway (i.e. generation of DAG from MAG via MAG transferases 1 and 2 (Mogat1/2 in mice)), may be a relevant pathway in NAFLD (Hall et al. 2012, Mashek 2013). Examination of the expression of the key genes involved in TAG synthesis revealed that there was an overall inhibitory effect of aLivPPAR $\gamma \mathrm{kd}$ on the expression of Mogat1 (Supplementary Table 1) that reached significance with age and HF feeding (Fig. 3B), without a reduction in Gpat, Mogat2, Dgat1 or Dgat2 expression (Fig. 3B). Of note, Mogat1 has been reported to be a direct target of PPAR $\gamma$ (Lee et al. 2012, Yu et al. 2015) and in fact, expression of Mogat1 increases with age and HF feeding, $P$ value:
0.0063 and <0.0001, respectively, (Supplementary Table $1 \mathrm{~A}$ and $\mathrm{B}$ ), mirroring the relative changes observed in hepatic PPAR $\gamma$ expression (Fig. 2). To indirectly test if the reduction in Mogat1 gene expression translated into a reduction in MAG pathway activity, we used LC/MS to measure the relative levels of MAG, DAG and TAG in LFand HF-fed mice with or without hepatic PPAR $\gamma$. Overall, aLivPPAR $\gamma$ kd increased MAG levels, which reached significance in LF-fed mice. In HF-fed aLivPPAR $\gamma \mathrm{kd}$ mice, this was associated with a decrease in DAG and TAG (Fig. 5B). Interestingly, in LF-fed aLivPPAR $\gamma \mathrm{kd}$, the relative levels of DAG and TAG were not altered. Taken together, loss of hepatocyte PPAR $\gamma$ signaling preferentially reduces the esterification of FA by direct transcriptional regulation of the MAG pathway, where loss of this effect could contribute to the protection against excess TAG accumulation observed in aLivPPAR $\gamma \mathrm{kd}$ mice.

\section{Discussion}

Hepatocyte PPAR $\gamma$ has been defined as a steatogenic factor (Rahimian et al. 2001, Gavrilova et al. 2003, Matsusue et al. 2003, Inoue et al. 2005, Moran-Salvador et al. 2011, Pettinelli \& Videla 2011), whereas others suggest that its activation decreases hepatic steatosis (Belfort et al. 2006, Ratziu et al. 2008, Sanyal et al. 2010). The fact that PPAR $\gamma$ is the target of TZDs that are used in 
the treatment of diabetes and NAFLD raises the question if the hepatic-specific agonism of PPAR $\gamma$ is well understood (Ahmadian et al. 2013). Therefore, we sought to determine which molecular processes are the primary targets for hepatocyte PPAR $\gamma$ that promotes TAG accumulation. We have taken advantage of the novel adult-onset, hepatocyte-specific PPAR $\gamma$ knockdown (aLivPPAR $\gamma$ kd) model that allowed us to study the early events altered by aLivPPAR $\gamma$ kd ( 1 week of knockdown), and how this deficit influences liver function overtime under different dietary conditions. Our approach has benefits over existing congenital knockout models because it avoids compensatory changes that could occur with embryonic knockout and therefore better models the consequence of manipulating PPAR $\gamma$ function in adults, where NAFLD/ NASH typically develops. As discussed in detail below, our primary findings are that hepatic PPAR $\gamma$ has minimal direct effects on hepatic DNL, TAG uptake, TAG export or FA oxidation, but plays a major role in upregulating genes/pathways critical for hepatic FA uptake- and MAG pathway-mediated FA esterification.

Congenital hepatocyte-specific PPAR $\gamma$ knockout has been reported to be associated with a reduction of hepatic expression of genes critical for DNL (Gavrilova et al. 2003, Matsusue et al. 2003, Yu et al. 2003, Moran-Salvador et al. 2011). Also, use of antisense oligonucleotide strategy to suppress elevated hepatic PPAR $\gamma$ in apoB/BATless mice, reduced hepatic TAG accumulation, as well as the expression of DNL genes and DNL rate as assessed by ${ }^{3} \mathrm{H}_{2} \mathrm{O}$ incorporation into TAG-associated FA (Zhang et al. 2006). In addition, overexpression of PPAR $\gamma$ in a hepatic cell line (AML-12; Schadinger et al. 2005) was shown to increase SREBP1c and Fasn expression that was associated with an increase in ${ }^{14} \mathrm{C}$-acetate incorporation into TAG. Finally, overexpression of PPAR $\gamma$ in some (Yu et al. 2003), but not all (Bai et al. 2011) in vivo models, increased the expression of genes associated with DNL. In contrast to these reports, in the aLivPPAR $\gamma \mathrm{kd}$ model system, expression of DNL genes were not suppressed in any conditions tested, consistent with the lack of an effect on DNL indices (16:1/16:0 and 16:0/18:2). In fact, we have recently reported that although $\operatorname{PPAR} \gamma$ expression was associated with TAG accumulation in a model of DNLgenerated steatosis (Kineman et al. 2016), adult-onset hepatic PPAR $\gamma$ knockdown in this steatotic model did not reduce hepatic TAG content or FA indices of DNL (Cordoba-Chacon et al. 2015a). The question arises, why are our current results counter to that previously reported by others? We might speculate that any changes observed in the expression of DNL genes in congenital liver-specific
PPAR $\gamma$-knockout models could be secondary to changes that occur due to compensation during development or systemic metabolic changes that occur overtime. Also, the use of antisense oligonucleotides (ASO) to acutely suppress enhanced PPAR $\gamma$ expression in vivo (Zhang et al. 2006) is not a hepatocyte-specific approach, and therefore, a reduction in PPAR $\gamma$ in other cell types could contribute to the phenotype observed. Finally in vivo (Zhang et al. 2006) or in vitro (Schadinger et al. 2005) overexpression of PPAR $\gamma$ may have off-target effects. Therefore, we can conclude that in the context of adult metabolic function, loss of hepatic PPAR $\gamma$ does not directly control hepatic DNL.

Early work by Gavrilova and coworkers and Matsusue and coworkers who crossbred the congenital liver-specific PPAR $\gamma$ model with a lipodystrophic model (AZIP; Gavrilova et al. 2003), and ob/ob mice (Matsusue et al. 2003), respectively, observed a reduction in hepatic TAG content associated with elevated plasma TAG and thus concluded that hepatic PPAR $\gamma$ was critical to maintain hepatic TAG uptake. However, in chow-fed WT mice (Matsusue et al. 2003, Moran-Salvador et al. 2011) and HF-fed (Moran-Salvador et al. 2011) mice with congenital liver-specific PPAR $\gamma$ knockout, as well as in our HF-fed aLivPPAR $\gamma \mathrm{kd}$ model, circulating TAG did not differ from PPAR $\gamma$-intact controls, despite the dramatic reduction in hepatic TAG content. Also, there were no decreases in the expression of genes known to be critical in hepatic TAG uptake in mouse livers, including lowdensity lipoprotein receptor (Ldlr; Ishibashi et al. 1994, Havel \& Hamilton 2004) and hepatic lipase (HL; Havel \& Hamilton 2004, Freeman et al. 2007). However, it should be noted that the expression of very low-density lipoprotein receptor (Vldr), a known PPAR $\gamma$ target in adipocytes (Tao et al. 2010), was significantly reduced in HF-fed aLivPPAR $\gamma \mathrm{kd}$ mice. The expression of hepatic Vldlr is normally low, but is increased in mouse models of fatty liver (also observed with HF feeding in this study, see Supplementary Table 1), and whole-body knockout of Vldlr reduces ER stress and HF diet-induced hepatic steatosis (Jo et al. 2013). However, a liver-specific role of Vldlr in hepatic TAG uptake remains to be determined. Although the role of PPAR $\gamma$ in regulating hepatic TAG uptake remains to be further explored, our current results coupled with previous reports, do provide compelling evidence that hepatic PPAR $\gamma$ promotes hepatic FA uptake by regulating the expression of Cd36. Specifically, in both aged and HF-fed aLivPPAR $\gamma \mathrm{kd}$ mice, expression of Cd36 was reduced. Cd36 has been shown to be a direct target of PPAR $\gamma$ (Tontonoz et al. 1998) and its

Published by Bioscientifica Ltd. 
expression is increased in steatotic livers. In the current study, a reduction in Cd36 levels in aLivPPAR $\gamma \mathrm{kd}$ mice was only observed with age or HF feeding, consistent with the fact that in addition to PPAR $\gamma$, LXR and PXR are also required for the full expression of Cd36 (Zhou et al. 2008). Although global Cd36 knockout does not protect against high fructose-induced hepatic steatosis (Hajri et al. 2002) or prevent fatty liver in ob/ob mice (Nassir et al. 2013), a more recent report supports a liverspecific role of Cd36 in FA uptake. Specifically, congenital liver-specific Cd36 knockout reduced steatosis in liverspecific Jak2 knockout mice that led to an increase in plasma NEFA (Wilson et al. 2015). Also in that same study, liver-specific Cd36-knockout mice with intact hepatic Jak2, dramatically reduced HF diet-induced steatosis that was associated with a reduction in hepatic FA uptake as measured by hepatic accumulation of BODIPY-FA in vivo (Wilson et al. 2015). However, loss of hepatic Cd36 did not entirely prevent hepatic FA uptake, which could be mediated by other facilitated transport mechanisms or passive diffusion (Glatz et al. 2010), indicating the reduction in CD36 after aLivPPAR $\gamma$ kd is only in part responsible for the reduction in hepatic TAG content.

Of the selected genes examined in this study, the expression of Mogat1 was the most sensitive to PPAR $\gamma$ loss. As previously reported, the expression of Mogat1 in the lean mouse liver is low, but increases in association with TAG accumulation, similar to that observed for PPAR $\gamma$ (Lee et al. 2012, Hall et al. 2014, Soufi et al. 2014, Yu et al. 2016), as we also observed in the current study. In addition, hepatic expression of Mogat1, as well as PPAR $\gamma$, is elevated in humans with NAFLD (Hall et al. 2012, Yu et al. 2015). There is an ongoing debate regarding the physiologic role hepatic Mogat1 plays in TAG synthesis as it was originally thought that the glycerol-3-phosphate pathway, not the MAG pathway, is the dominant route to form TAG in the liver (Coleman \& Mashek 2011, Mashek 2013). In fact, one laboratory could not detect hepatic MOGAT activity (Cortes et al. 2009) and recently reported that global Mogat1 knockout in the ob/ob or Agpat2KO mice did not impact steatosis (Agarwal et al. 2016). However, hepatic MOGAT activity has been detected by other laboratories (Yen et al. 2002, Hall et al. 2012). Importantly, the increase in Mogat1 expression observed in HF-fed and ob/ob mice is associated with an elevation of hepatic MOGAT activity, which is reduced by Mogat1 ASO ip treatment (Hall et al. 2014, Soufi et al. 2014). The Mogat1-ASO injections reduced hepatic TAG accumulation in one study (Soufi et al. 2014), but not the other (Hall et al. 2014). However, it was acknowledged that the knockdown of Mogat1 was not hepatocyte specific, and actually led to a reduction in Mogat1 expression in the adipose tissue that could offset any hepatocytespecific effect (Soufi et al. 2014). In strong support of a physiologic role of hepatic Mogat1 in maintaining hepatic TAG levels, adenoviral shRNA-Mogat1 delivery (that is preferentially taken up by the liver) (Lee et al. 2012), and nonviral siRNA-Mogat1 delivery (Hayashi et al. 2014), reduced Mogat1 expression and hepatic TAG levels in HF-fed mice. The results of the present study indicate that PPAR $\gamma$ is necessary to maintain Mogat1 activity, as well as Mogat1 expression, based on the increase in hepatic MAG levels in aLivPPAR $\gamma \mathrm{kd}$ mice. Interestingly, it has been postulated that Mogat1 may prefer extrahepatic (dietary FA) over those produced by hepatic DNL, to synthesize DAG (Steneberg et al. 2015). This would be consistent with our observation that although MAG levels were increased in LF-fed aLivPPAR $\gamma \mathrm{kd}$ mice, DAG and TAG levels were normal, where in this context, hepatic DAG and TAG are mainly derived from DNL. However, in HF-fed aLivPPAR $\gamma$ kd mice (where the bulk of FA is coming from the diet), a reduction in DAG and TAG levels was observed.

Taken together, results suggest that hepatocyte PPAR $\gamma$ expression in adult livers is not essential to maintain the expression of DNL genes, but it is essential to induce the expression of genes important in hepatic FA uptake (Cd36) and re-esterification (Mogat1). Certainly, other pathways may be mediated by hepatic PPAR $\gamma$ that were not revealed by our targeted approach. Nonetheless, our current data, coupled with previous reports suggest that impairment of the Cd36-mediated FA uptake and FA esterification by MAG pathway could explain in part the protection against steatosis observed in aLivPPAR $\gamma \mathrm{kd}$ mice.

\section{Supplementary data}

This is linked to the online version of the paper at http://dx.doi.org/10.1530/ JOE-16-0447.

\section{Declaration of interest}

The authors declare that there is no conflict of interest that could be perceived as prejudicing the impartiality of the research reported.

\section{Funding}

This work was supported by Department of Veterans Affairs, Office of Research and Development Merit Award (BX001090, BX001114), National Institutes of Health (R21AT008457, S10OD010660, R01DK088133), Chicago Biomedical Consortium with support from the Searle Funds at The 
Chicago Community Trust (PDR-033), Pilot Grant through UIC CCTS (NIHUL1TR000050), West Side Institute for Science and Education (WISE), and 2014 Endocrine Scholar Award in Growth Hormone Research (Endocrine Society).

\section{References}

Agarwal AK, Tunison K, Dalal JS, Yen CL, Farese RV Jr, Horton JD \& Garg A 2016 Mogat1 deletion does not ameliorate hepatic steatosis in lipodystrophic (Agpat2-/-) or obese (ob/ob) mice. Journal of Lipid Research 57 616-630. (doi:10.1194/jlr.M065896)

Ahmadian M, Suh JM, Hah N, Liddle C, Atkins AR, Downes M \& Evans RM 2013 PPARgamma signaling and metabolism: the good, the bad and the future. Nature Medicine 19 557-566. (doi:10.1038/nm.3159)

Ashpole NM, Herron JC, Mitschelen MC, Farley JA, Logan S, Yan H, Ungvari Z, Hodges EL, Csiszar A, Ikeno Y, et al. 2016 IGF-1 regulates vertebral bone aging through sex-specific and time-dependent mechanisms. Journal of Bone and Mineral Research 31 443-454. (doi:10.1002/jbmr.2689)

Bai L, Jia Y, Viswakarma N, Huang J, Vluggens A, Wolins NE, Jafari N, Rao MS, Borensztajn J, Yang G, et al. 2011 Transcription coactivator mediator subunit MED1 is required for the development of fatty liver in the mouse. Hepatology 53 1164-1174 (doi:10.1002/hep.24155)

Belfort R, Harrison SA, Brown K, Darland C, Finch J, Hardies J, Balas B, Gastaldelli A, Tio F, Pulcini J, et al. 2006 A placebo-controlled trial of pioglitazone in subjects with nonalcoholic steatohepatitis. New England Journal of Medicine 355 2297-2307. (doi:10.1056/ NEJMoa060326)

Benard O, Lim J, Apontes P, Jing X, Angeletti RH \& Chi Y 2016 Impact of high-fat diet on the proteome of mouse liver. Journal of Nutritional Biochemistry 31 10-19. (doi:10.1016/j.jnutbio.2015.12.012)

Beysen C, Murphy EJ, Nagaraja H, Decaris M, Riiff T, Fong A, Hellerstein MK \& Boyle PJ 2008 A pilot study of the effects of pioglitazone and rosiglitazone on de novo lipogenesis in type 2 diabetes. Journal of Lipid Research 49 2657-2663. (doi:10.1194/jlr. M800165-JLR200)

Bligh EG \& Dyer WJ 1959 A rapid method of total lipid extraction and purification. Canadian Journal of Biochemistry and Physiology 37 911-917. (doi:10.1139/o59-099)

Browning JD \& Horton JD 2004 Molecular mediators of hepatic steatosis and liver injury. Journal of Clinical Investigation 114 147-152. (doi:10.1172/JCI200422422)

Coleman RA \& Mashek DG 2011 Mammalian triacylglycerol metabolism: synthesis, lipolysis, and signaling. Chemical Reviews 111 6359-6386. (doi:10.1021/cr100404w)

Cordoba-Chacon J, Gahete MD, McGuinness OP \& Kineman RD $2014 a$ Differential impact of selective GH deficiency and endogenous GH excess on insulin-mediated actions in muscle and liver of male mice. American Journal of Physiology: Endocrinology and Metabolism $\mathbf{3 0 7}$ E928-E934. (doi:10.1152/ajpendo.00420.2014)

Cordoba-Chacon J, Gahete MD, Pokala NK, Geldermann D, Alba M, Salvatori R, Luque RM \& Kineman RD $2014 b$ Long- but not short-term adult-onset, isolated GH deficiency in male mice leads to deterioration of beta-cell function, which cannot be accounted for by changes in beta-cell mass. Endocrinology 155 726-735. (doi:10.1210/en.2013-1825)

Cordoba-Chacon J, Majumdar N, List EO, Diaz-Ruiz A, Frank SJ, Manzano A, Bartrons R, Puchowicz M, Kopchick JJ \& Kineman RD $2015 a$ Growth hormone inhibits hepatic de novo lipogenesis in adult mice. Diabetes 64 3093-3103. (doi:10.2337/db15-0370)

Cordoba-Chacon J, Majumdar N, Pokala NK, Gahete MD \& Kineman RD $2015 b$ Islet insulin content and release are increased in male mice with elevated endogenous GH and IGF-I, without evidence of systemic insulin resistance or alterations in beta-cell mass.

http://joe.endocrinology-journals.org

DOI: $10.1530 / J O E-16-0447$ (c) 2017 Society for Endocrinology Printed in Great Britain
Growth Hormone and IGF Research 25 189-195. (doi:10.1016/j. ghir.2015.04.002)

Cortes VA, Curtis DE, Sukumaran S, Shao X, Parameswara V, Rashid S, Smith AR, Ren J, Esser V, Hammer RE, et al. 2009 Molecular mechanisms of hepatic steatosis and insulin resistance in the AGPAT2-deficient mouse model of congenital generalized lipodystrophy. Cell Metabolism 9 165-176. (doi:10.1016/j. cmet.2009.01.002)

Duarte JA, Carvalho F, Pearson M, Horton JD, Browning JD, Jones JG \& Burgess SC 2014 A high-fat diet suppresses de novo lipogenesis and desaturation but not elongation and triglyceride synthesis in mice. Journal of Lipid Research 55 2541-2553. (doi:10.1194/jlr.M052308)

Freeman L, Amar MJ, Shamburek R, Paigen B, Brewer HB Jr, SantamarinaFojo S \& Gonzalez-Navarro H 2007 Lipolytic and ligand-binding functions of hepatic lipase protect against atherosclerosis in LDL receptor-deficient mice. Journal of Lipid Research 48 104-113. (doi:10.1194/jlr.M600321-JLR200)

Furnsinn C \& Waldhausl W 2002 Thiazolidinediones: metabolic actions in vitro. Diabetologia 45 1211-1223. (doi:10.1007/s00125-002-0899-1)

Gavrilova O, Haluzik M, Matsusue K, Cutson JJ, Johnson L, Dietz KR, Nicol CJ, Vinson C, Gonzalez FJ \& Reitman ML 2003 Liver peroxisome proliferator-activated receptor gamma contributes to hepatic steatosis, triglyceride clearance, and regulation of body fat mass. Journal of Biological Chemistry 278 34268-34276. (doi:10.1074/ jbc.M300043200)

Glatz JF, Luiken JJ \& Bonen A 2010 Membrane fatty acid transporters as regulators of lipid metabolism: implications for metabolic disease. Physiological Reviews 90 367-417. (doi:10.1152/physrev.00003.2009)

Guo J, Jou W, Gavrilova O \& Hall KD 2009 Persistent diet-induced obesity in male $\mathrm{C} 57 \mathrm{BL} / 6$ mice resulting from temporary obesigenic diets. PLOS ONE 4 e5370. (doi:10.1371/journal.pone.0005370)

Gupte AA, Liu JZ, Ren Y, Minze LJ, Wiles JR, Collins AR, Lyon CJ, Pratico D, Finegold MJ, Wong ST, et al. 2010 Rosiglitazone attenuates age- and diet-associated nonalcoholic steatohepatitis in male low-density lipoprotein receptor knockout mice. Hepatology 52 2001-2011. (doi:10.1002/hep.23941)

Hajri T, Han XX, Bonen A \& Abumrad NA 2002 Defective fatty acid uptake modulates insulin responsiveness and metabolic responses to diet in CD36-null mice. Journal of Clinical Investigation 109 1381-1389. (doi:10.1172/JCI0214596)

Hall AM, Kou K, Chen Z, Pietka TA, Kumar M, Korenblat KM, Lee K, Ahn K, Fabbrini E, Klein S, et al. 2012 Evidence for regulated monoacylglycerol acyltransferase expression and activity in human liver. Journal of Lipid Research 53 990-999. (doi:10.1194/jlr. P025536)

Hall AM, Soufi N, Chambers KT, Chen Z, Schweitzer GG, McCommis KS, Erion DM, Graham MJ, Su X \& Finck BN 2014 Abrogating monoacylglycerol acyltransferase activity in liver improves glucose tolerance and hepatic insulin signaling in obese mice. Diabetes 63 2284-2296. (doi:10.2337/db13-1502)

Havel RJ \& Hamilton RL 2004 Hepatic catabolism of remnant lipoproteins: where the action is. Arteriosclerosis Thrombosis and Vascular Biology 24 213-215. (doi:10.1161/01. ATV.0000115382.53810.24)

Hayashi Y, Suemitsu E, Kajimoto K, Sato Y, Akhter A, Sakurai Y, Hatakeyama H, Hyodo M, Kaji N, Baba Y, et al. 2014 Hepatic monoacylglycerol O-acyltransferase 1 as a promising therapeutic target for steatosis, obesity, and type 2 diabetes. Molecular Therapy: Nucleic Acids 3 e154. (doi:10.1038/mtna.2014.4)

He W, Barak Y, Hevener A, Olson P, Liao D, Le J, Nelson M, Ong E, Olefsky JM \& Evans RM 2003 Adipose-specific peroxisome proliferator-activated receptor gamma knockout causes insulin resistance in fat and liver but not in muscle. PNAS 100 15712-15717. (doi:10.1073/pnas.2536828100)

Horakova O, Hansikova J, Bardova K, Gardlo A, Rombaldova M, Kuda O, Rossmeisl M \& Kopecky J 2016 Plasma acylcarnitines and amino 
acid levels as an early complex biomarker of propensity to high-fat diet-induced obesity in mice. PLoS ONE 11 e0155776. (doi:10.1371/ journal.pone.0155776)

Inoue M, Ohtake T, Motomura W, Takahashi N, Hosoki Y, Miyoshi S, Suzuki Y, Saito H, Kohgo Y \& Okumura T 2005 Increased expression of PPARgamma in high fat diet-induced liver steatosis in mice. Biochemical and Biophysical Research Communications 336 215-222. (doi:10.1016/j.bbrc.2005.08.070)

Ishibashi S, Herz J, Maeda N, Goldstein JL \& Brown MS 1994 The two-receptor model of lipoprotein clearance: tests of the hypothesis in 'knockout' mice lacking the low density lipoprotein receptor, apolipoprotein E, or both proteins. PNAS 91 4431-4435. (doi:10.1073/pnas.91.10.4431)

Jo H, Choe SS, Shin KC, Jang H, Lee JH, Seong JK, Back SH \& Kim JB 2013 Endoplasmic reticulum stress induces hepatic steatosis via increased expression of the hepatic very low-density lipoprotein receptor. Hepatology 57 1366-1377. (doi:10.1002/hep.26126)

Kineman R, Majumdar N, Subbaiah PV \& Cordoba-Chacon J 2016 Hepatic PPAR $\gamma$ is not essential for the rapid development of steatosis following loss of hepatic GH signaling, in adult male mice. Endocrinology 157 1728-1735. (doi:10.1210/en.2015-2077)

Lade A, Noon LA \& Friedman SL 2014 Contributions of metabolic dysregulation and inflammation to nonalcoholic steatohepatitis, hepatic fibrosis, and cancer. Current Opinion in Oncology 26 100-107. (doi:10.1097/CCO.0000000000000042)

Lee YJ, Ko EH, Kim JE, Kim E, Lee H, Choi H, Yu JH, Kim HJ, Seong JK, Kim KS, et al. 2012 Nuclear receptor PPARgamma-regulated monoacylglycerol O-acyltransferase 1 (MGAT1) expression is responsible for the lipid accumulation in diet-induced hepatic steatosis. PNAS 109 13656-13661. (doi:10.1073/pnas.1203218109)

Lee JJ, Lambert JE, Hovhannisyan Y, Ramos-Roman MA, Trombold JR, Wagner DA \& Parks EJ 2015 Palmitoleic acid is elevated in fatty liver disease and reflects hepatic lipogenesis. American Journal of Clinical Nutrition 101 34-43. (doi:10.3945/ajcn.114.092262)

Mashek DG 2013 Hepatic fatty acid trafficking: multiple forks in the road. Advances in Nutrition 4 697-710. (doi:10.3945/an.113.004648)

Matsusue K, Haluzik M, Lambert G, Yim SH, Gavrilova O, Ward JM, Brewer B Jr, Reitman ML \& Gonzalez FJ 2003 Liver-specific disruption of PPARgamma in leptin-deficient mice improves fatty liver but aggravates diabetic phenotypes. Journal of Clinical Investigation 111 737-747. (doi:10.1172/JCI200317223)

Matsusue K, Aibara D, Hayafuchi R, Matsuo K, Takiguchi S, Gonzalez FJ \& Yamano S 2014 Hepatic PPARgamma and LXRalpha independently regulate lipid accumulation in the livers of genetically obese mice. FEBS Letters 588 2277-2281. (doi:10.1016/j.febslet.2014.05.012)

Michelotti GA, Machado MV \& Diehl AM 2013 NAFLD, NASH and liver cancer. Nature Reviews Gastroenterology and Hepatology 10 656-665. (doi:10.1038/nrgastro.2013.183)

Moran-Salvador E, Lopez-Parra M, Garcia-Alonso V, Titos E, Martinez-Clemente M, Gonzalez-Periz A, Lopez-Vicario C, Barak Y, Arroyo V \& Claria J 2011 Role for PPARgamma in obesity-induced hepatic steatosis as determined by hepatocyte- and macrophagespecific conditional knockouts. FASEB Journal 25 2538-2550. (doi:10.1096/fj.10-173716)

Nan YM, Fu N, Wu WJ, Liang BL, Wang RQ, Zhao SX, Zhao JM \& Yu J 2009 Rosiglitazone prevents nutritional fibrosis and steatohepatitis in mice. Scandinavian Journal of Gastroenterology 44 358-365. (doi:10.1080/00365520802530861)

Nassir F, Adewole OL, Brunt EM \& Abumrad NA 2013 CD36 deletion reduces VLDL secretion, modulates liver prostaglandins, and exacerbates hepatic steatosis in ob/ob mice. Journal of Lipid Research 54 2988-2997. (doi:10.1194/jlr.M037812)

Obrowsky S, Chandak PG, Patankar JV, Povoden S, Schlager S, Kershaw EE, Bogner-Strauss JG, Hoefler G, Levak-Frank S \& Kratky D 2013 Adipose triglyceride lipase is a TG hydrolase of the small intestine and regulates intestinal PPARalpha signaling. Journal of Lipid Research 54 425-435. (doi:10.1194/jlr.M031716)

Pettinelli P \& Videla LA 2011 Up-regulation of PPAR-gamma mRNA expression in the liver of obese patients: an additional reinforcing lipogenic mechanism to SREBP-1c induction. Journal of Clinical Endocrinology and Metabolism 96 1424-1430. (doi:10.1210/jc.20102129)

Rahimian R, Masih-Khan E, Lo M, van Breemen C, McManus BM \& Dube GP 2001 Hepatic over-expression of peroxisome proliferator activated receptor gamma2 in the ob/ob mouse model of non-insulin dependent diabetes mellitus. Molecular and Cellular Biochemistry 224 29-37. (doi:10.1023/A:1011927113563)

Ratziu V, Giral P, Jacqueminet S, Charlotte F, Hartemann-Heurtier A, Serfaty L, Podevin P, Lacorte JM, Bernhardt C, Bruckert E, et al. 2008 Rosiglitazone for nonalcoholic steatohepatitis: one-year results of the randomized placebo-controlled Fatty Liver Improvement with Rosiglitazone Therapy (FLIRT) Trial. Gastroenterology 135 100-110. (doi:10.1053/j.gastro.2008.03.078)

Sanyal AJ, Chalasani N, Kowdley KV, McCullough A, Diehl AM, Bass NM, Neuschwander-Tetri BA, Lavine JE, Tonascia J, Unalp A, et al. 2010 Pioglitazone, vitamin E, or placebo for nonalcoholic steatohepatitis. New England Journal of Medicine 362 1675-1685. (doi:10.1056/ NEJMoa0907929)

Schadinger SE, Bucher NL, Schreiber BM \& Farmer SR 2005 PPARgamma2 regulates lipogenesis and lipid accumulation in steatotic hepatocytes. American Journal of Physiology: Endocrinology and Metabolism 288 E1195-E1205. (doi:10.1152/ajpendo.00513.2004)

Sevastianova K, Santos A, Kotronen A, Hakkarainen A, Makkonen J, Silander K, Peltonen M, Romeo S, Lundbom J, Lundbom N, et al. 2012 Effect of short-term carbohydrate overfeeding and long-term weight loss on liver fat in overweight humans. American Journal of Clinical Nutrition 96 727-734. (doi:10.3945/ajcn.112.038695)

Shin S, Wangensteen KJ, Teta-Bissett M, Wang YJ, Mosleh-Shirazi E, Buza EL, Greenbaum LE \& Kaestner KH 2016 Genetic lineage tracing analysis of the cell of origin of hepatotoxin-induced liver tumors in mice. Hepatology 64 1163-1177. (doi:10.1002/hep.28602)

Silbernagel G, Kovarova M, Cegan A, Machann J, Schick F, Lehmann R, Haring HU, Stefan N, Schleicher E, Fritsche A, et al. 2012 High hepatic SCD1 activity is associated with low liver fat content in healthy subjects under a lipogenic diet. Journal of Clinical Endocrinology and Metabolism 97 E2288-E2292. (doi:10.1210/jc.2012-2152)

Soufi N, Hall AM, Chen Z, Yoshino J, Collier SL, Mathews JC, Brunt EM, Albert CJ, Graham MJ, Ford DA, et al. 2014 Inhibiting monoacylglycerol acyltransferase 1 ameliorates hepatic metabolic abnormalities but not inflammation and injury in mice. Journal of Biological Chemistry 289 30177-30188. (doi:10.1074/jbc. M114.595850)

Steneberg P, Sykaras AG, Backlund F, Straseviciene J, Soderstrom I \& Edlund H 2015 Hyperinsulinemia enhances hepatic expression of the fatty acid transporter Cd36 and provokes hepatosteatosis and hepatic insulin resistance. Journal of Biological Chemistry 290 19034-19043. (doi:10.1074/jbc.M115.640292)

Tao H, Aakula S, Abumrad NN \& Hajri T 2010 Peroxisome proliferatoractivated receptor-gamma regulates the expression and function of very-low-density lipoprotein receptor. American Journal of Physiology: Endocrinology and Metabolism 298 E68-E79. (doi:10.1152/ ajpendo.00367.2009)

Tontonoz P, Nagy L, Alvarez JG, Thomazy VA \& Evans RM 1998 PPARgamma promotes monocyte/macrophage differentiation and uptake of oxidized LDL. Cell 93 241-252. (doi:10.1016/S00928674(00)81575-5)

Wilson CG, Tran JL, Erion DM, Vera NB, Febbraio M \& Weiss EJ 2015 Hepatocyte-specific disruption of CD36 attenuates fatty liver and improves insulin sensitivity in HFD fed mice. Endocrinology 157 570-585. (doi:10.1210/en.2015-1866) http://joe.endocrinology-journals.org

DOI: 10.1530/JOE-16-0447
๑ 2017 Society for Endocrinology Printed in Great Britain 
Xu A, Wang Y, Keshaw H, Xu LY, Lam KS \& Cooper GJ 2003 The fat-derived hormone adiponectin alleviates alcoholic and nonalcoholic fatty liver diseases in mice. Journal of Clinical Investigation 112 91-100. (doi:10.1172/JCI200317797)

Yamauchi T, Kamon J, Minokoshi Y, Ito Y, Waki H, Uchida S, Yamashita S, Noda M, Kita S, Ueki K, et al. 2002 Adiponectin stimulates glucose utilization and fatty-acid oxidation by activating AMP-activated protein kinase. Nature Medicine 8 1288-1295. (doi:10.1038/nm788)

Yamazaki T, Shiraishi S, Kishimoto K, Miura S \& Ezaki O 2011 An increase in liver PPARgamma2 is an initial event to induce fatty liver in response to a diet high in butter: PPARgamma2 knockdown improves fatty liver induced by high-saturated fat. Journal of Nutritional Biochemistry 22 543-553. (doi:10.1016/j.jnutbio.2010.04.009)

Yang P \& Subbaiah PV 2015 Regulation of hepatic lipase activity by sphingomyelin in plasma lipoproteins. Biochimica et Biophysica Acta 1851 1327-1336. (doi:10.1016/j.bbalip.2015.07.003)

Yanger K, Knigin D, Zong Y, Maggs L, Gu G, Akiyama H, Pikarsky E \& Stanger BZ 2014 Adult hepatocytes are generated by self-duplication rather than stem cell differentiation. Cell Stem Cell 15 340-349. (doi:10.1016/j.stem.2014.06.003)

Yen CL, Stone SJ, Cases S, Zhou P \& Farese RV Jr 2002 Identification of a gene encoding MGAT1, a monoacylglycerol acyltransferase. PNAS 99 8512-8517. (doi:10.1073/pnas.132274899)

Younossi ZM, Stepanova M, Afendy M, Fang Y, Younossi Y, Mir H \& Srishord M 2011 Changes in the prevalence of the most common causes of chronic liver diseases in the United States from 1988 to 2008. Clinical Gastroenterology and Hepatology 9 524-530.e521; quiz e560. (doi:10.1016/j.cgh.2011.03.020)
Yu S, Matsusue K, Kashireddy P, Cao WQ, Yeldandi V, Yeldandi AV, Rao MS, Gonzalez FJ \& Reddy JK 2003 Adipocyte-specific gene expression and adipogenic steatosis in the mouse liver due to peroxisome proliferator-activated receptor gamma1 (PPARgamma1) overexpression. Journal of Biological Chemistry 278 498-505. (doi:10.1074/jbc.M210062200)

Yu JH, Lee YJ, Kim HJ, Choi H, Choi Y, Seok JW \& Kim JW 2015 Monoacylglycerol O-acyltransferase 1 is regulated by peroxisome proliferator-activated receptor gamma in human hepatocytes and increases lipid accumulation. Biochemical and Biophysical Research Communications 460 715-720. (doi:10.1016/j. bbrc.2015.03.095)

Yu JH, Song SJ, Kim A, Choi Y, Seok JW, Kim HJ, Lee YJ, Lee KS \& Kim JW 2016 Suppression of PPARgamma-mediated monoacylglycerol O-acyltransferase 1 expression ameliorates alcoholic hepatic steatosis. Scientific Reports 6 29352. (doi:10.1038/srep29352)

Zezos P \& Renner EL 2014 Liver transplantation and non-alcoholic fatty liver disease. World Journal of Gastroenterology 20 15532-15538. (doi:10.3748/wjg.v20.i42.15532)

Zhang YL, Hernandez-Ono A, Siri P, Weisberg S, Conlon D, Graham MJ, Crooke RM, Huang LS \& Ginsberg HN 2006 Aberrant hepatic expression of PPARgamma2 stimulates hepatic lipogenesis in a mouse model of obesity, insulin resistance, dyslipidemia, and hepatic steatosis. Journal of Biological Chemistry 281 37603-37615. (doi:10.1074/jbc.M604709200)

Zhou J, Febbraio M, Wada T, Zhai Y, Kuruba R, He J, Lee JH, Khadem S, Ren S, Li S, et al. 2008 Hepatic fatty acid transporter Cd36 is a common target of LXR, PXR, and PPARgamma in promoting steatosis. Gastroenterology 134 556-567. (doi:10.1053/j.gastro.2007.11.037)

Received in final form 5 October 2016

Accepted 25 October 2016

Accepted Preprint published online 31 October 2016
๑) 2017 Society for Endocrinology Printed in Great Britain 